\title{
Predictors of neonatal mortality in Assosa zone, Western Ethiopia: a matched case control study
}

\author{
Fillmon Kidus ${ }^{1 *}$ D, Kifle Woldemichael ${ }^{2}$ and Desta Hiko ${ }^{2}$
}

\begin{abstract}
Background: Benshangul Gumuze region is one of the regional states in Ethiopia, with highest rate of neonatal mortality rate. The trend increased at alarming rate from 42/1000 live birth in 2005 to 62/ 1000 live birth in 2011. Hence, identifying predictors of neonatal death and implement evidence based interventions at community level is crucial to reduce the mortality. Therefore, the purpose of this study was to identify predictors of neonatal mortality in Assosa zone, Western Ethiopia.

Methods: A community based matched case control study was conducted from February 1, until December 30, 2013. The study included 114 cases who died during the first 28 completed days after birth from September 1 , 2010 till September 1, 2013. For each case, one alive control matched approximately by the same date of birth (-/+ 2 days) was identified from the preliminary data collected. Finally, multivariate conditional logistic regression analysis was performed; and goodness of fit of the final model was tested using likely hood ratio test. All analysis was done using EPI Info version 7 and SPSS version 16 statistical softwares.
\end{abstract}

Results: Model households in health extension packages [AmOR $=0.32 ; 95 \% \mathrm{Cl}: 0.12-0.86$ ], age at first pregnancy $<20$ years old $[\mathrm{AmOR}=4.3 ; 95 \% \mathrm{Cl}: 1.13-16.27$, pregnancy complication $[\mathrm{AmOR}=4.59 ; 95 \% \mathrm{Cl}$ : 1.53-13.78], delivery complication $[\mathrm{AmOR}=2.80 ; 95 \% \mathrm{Cl}: 1.06-7.39]$, antenatal care visit $[\mathrm{AmOR}=0.34 ; 95 \% \mathrm{Cl}: 0.12-0.94]$, primipara mothers [AmOR $=3.37 ; 95 \% \mathrm{Cl}: 1.05-10.78]$, small size neonate at birth [AmOR $=3.40: 95 \% \mathrm{Cl}: 1.05-11.55]$, gestational age $<37$ weeks [AmOR $=4.35 ; 95 \% \mathrm{Cl}: 1.16-16.28]$, and home delivery [AmOR $=2.84 ; 95 \% \mathrm{Cl}: 1.07-7.55]$ were found statistically significantly associated with neonatal mortality.

Conclusions: Model households in health extension package and antenatal care visit were associated with reducing risk of neonatal mortality. However, age at first pregnancy $<20$ years old, primipara mothers, pregnancy complication, delivery complication, small size neonates, gestational age $<37$ weeks, and home delivery were associated with increasing risk of neonatal death. Therefore, promotion of model household in health extension package, anti natal care visit, institutional delivery, family planning to prevent early age pregnancy; and improve access to basic emergency obstetric care and intensive newborn care centers are effective interventions to reduce risk of neonatal mortality at community level.

Keywords: Neonatal mortality, Case control, Predictors

\footnotetext{
* Correspondence: fillmonebuy52@gmail.com

${ }^{1}$ Department of Disease Prevention and Health Promotion, Benshangul

Gumuze Regional Health Bureau, Assosa, Ethiopia

Full list of author information is available at the end of the article
}

(c) The Author(s). 2019 Open Access This article is distributed under the terms of the Creative Commons Attribution 4.0 International License (http://creativecommons.org/licenses/by/4.0/), which permits unrestricted use, distribution, and reproduction in any medium, provided you give appropriate credit to the original author(s) and the source, provide a link to the Creative Commons license, and indicate if changes were made. The Creative Commons Public Domain Dedication waiver (http://creativecommons.org/publicdomain/zero/1.0/) applies to the data made available in this article, unless otherwise stated. 


\section{Background}

According to World Health Organization definition, neonatal mortality (NM) is death among live births during the first 28 completed days of life [1]. This may subdivided into early neonatal death, which occur during the first seven days of life (0-6) and late neonatal death occur after the 7th day but before the 28th completed day of life (7-27) [1]. Neonatal period carries one of the highest risks of death in any 4-week period in the human lifespan [2].

Six million nine hundred thousand children died before reaching their fifth birthday globally in 2011; about $43 \%$ of this deaths was NM [3]. According to global estimate report, NM is highest in low-income countries and consistently decline with increasing regional income [4]. The heaviest burden is in South Asia and Sub-Saharan Africa; both have highest neonatal mortality rates (NMR) among all regions [4]. The countries in Sub-Saharan Africa (with some exceptions) have made little progress in decreasing such deaths in the past $10-15$ years $[3,5]$.

According to 2011 Ethiopian demographic and health survey (EDHS) report, national NMR in 2000, 2005 and 2011 were 49, 39 and 37 per 1000 live birth respectively $[6,7]$.

Benshangul Gumuze region is one of the regional states in Ethiopia with highest rate of NM; it was 62 per
1000 live birth in 2011 [7]. The rate was increased at alarm rate from 44 in 2005 to 62 per 1000 live birth in $2011[6,7]$. Assosa zone is one of the largest populated zone in the region with low coverage of maternal and child health services; such as, institutional delivery, model household in health extension packages, and antenatal care visit [8]. Thus, it might contribute in large proportion to the regional neonatal death profile.

The conceptual framework of this study was adapted from Mosley and Chin framework for the study of child survival in developing countries [9]. It has two major categories: distal and proximate factors. The distal factors were socio-demographic and economic characteristics. The proximate factors were leveled in to four subcategories: maternal biological and obstetric factors, neonatal factors, delivery and health system factors, and behavioral and psychosocial factors (Fig. 1).

Socio demographic and economic factors [10-20], maternal biological and obstetric factors such us: early age 1st pregnancy [17-20], delivery and pregnancy complications [18, 21-24], antenatal care (ANC) visit [18, 19, $21,24]$, parity [21, 23], and birth space $<24$ months [18, $24,25]$ were reported having statistical significant association with NM. In line with this, neonatal factors, like size at birth [21, 26-28], gestational age $(\mathrm{GA})<37$ weeks $[11,13,26,27]$, delivery and health system related

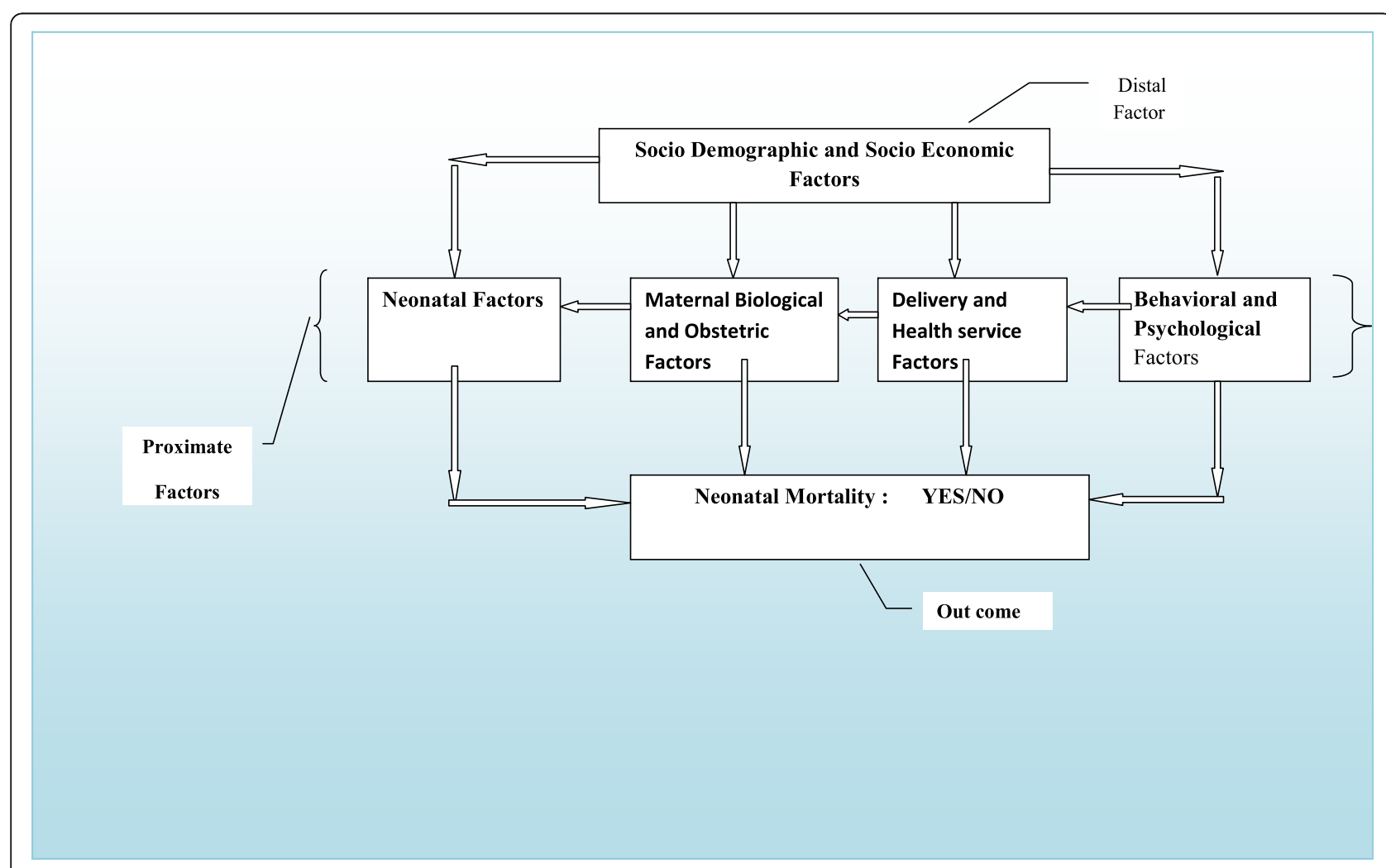

Fig. 1 Conceptual framework to study predicators of neonatal mortality, in Assosa zone, Western Ethiopia, 2013 
factors [16, 18, 21, 30-34], and behavioral and psychosocial factors $[35,36]$ were also shown statistically significantly associated with risk of NM.

In Ethiopia, there were few studies conducted at community level. However, they were only confined to demographic study areas [37, 38]. Moreover, one-size fits all approach is unlikely to work, because the effect of interventions must depend on the local cause-of-death profile and the health system platforms available there. Therefore, the main purpose of this study was to identify predictors of NM. Subsequently, it will add an immense value for efforts to reduce neonatal death in the region, by utilizing the findings of the study for planning and implementation of effective interventions at community level.

\section{Methods}

\section{Study setting, design and sampling}

A matched case control study was conducted in Assosa zone, Western Ethiopia from February 1 until December 30, 2013. Assosa zone is located $667 \mathrm{~km}$ to West of Addis Ababa. It has a population of 342,287; male 188,258 and female 154,029 (2007 census projected). The zone has 7 woredas (districts) and 72 kebeles (villages). The study population was sample of neonates who died during the first 28 completed days after birth and sample of neonates who survived the first 28 completed days after birth, from September 1, 2010 until September 1, 2013. Cases were neonates (index birth) who died during the first 28 completed days after birth and controls were neonates (index birth) who survived the first 28 completed days after birth and alive during data collection. Neonates, match the definition of case and control were eligible for the study. However, neonates born outside Assosa zone and neonates mothers who were sick or unable to communicate were excluded from the study.

Sample size of the study was determined by PS software version 3.0.43 power and sample size calculation for matched case control study. Different predictors were considered to determine the sample size. Thus, preterm birth was chosen, as it gave large sample size using parameters of $95 \%$ confidence interval (CI), $80 \%$ power, proportion of preterm birth among cases $\left(\mathrm{P}_{1}\right)$ was $48.5 \%$, and proportion of preterm birth among controls $\left(\mathrm{P}_{0}\right)$ was $8.2 \%$ [39]. The minimum detectable odds ratio was 3.5 and ratio of case to control (m) 1:1. Correlation coefficient $(r)$ for exposure between matched case and control was unknown; hence, 0.2-phi coefficient was taken on the assumption of dependency [40]. Adding 5\% contingency for non-response, the total sample size required for the study was 238(119 cases and 119 controls). With regard to sampling techniques, from the total seven woredas (districts) of the zone, four districts were selected first, then from each four districts, four kebeles (villages) were chosen. Simple random sampling method was used to choose both the districts and villages. As result, totally 16 villages were included in the study to get sufficient sample of cases (Fig. 2).

Preliminary data was collected from the 16 villages' health posts child health registration book, ahead of the actual study. Information was collected on the following variables: date of birth, date of death, household identification, place of birth and type of birth (singleton or multiple). Then, all live birth neonates who survived the first 28 completed days after birth and all live birth neonates who died during the first 28 completed days after birth from September 1, 2010 till September 1, 2013 were indentified. From the preliminary data result, 139 singleton cases were identified and eight cases were excluded based on the exclusion criteria listed (six cases were born outside Assosa zone and two mothers of cases were unable to communicate). Afterward, 131 eligible cases were identified and sampling frame was prepared. However, due to constraint of resource, only the required samples of 119 cases were selected using simple random sampling method. Finally, for each identified cases, one alive control was matched approximately by the same date of birth $(-/+2$ days $)$ from the preliminary data collected.

\section{Measurements}

Structured questionnaire was prepared in English by reviewing different literatures and adapting World Health Organization verbal autopsy to local context. Then, it was translated to Amharic and checked for consistency by back translation to English by different individuals. The questionnaire had five parts: socio demographic and economic characteristic, maternal biological and obstetric factors, neonatal factors, behavioral and psychosocial characteristics, and health service and delivery related factors.

Model households in health extension package was defined when the households were attended training on 16 health packages (personal hygiene, control of insect and rodents, healthy home environment, food hygiene and safety, water supply and safety, solid and liquid waste, safe excreta disposal, TB and HIV control, malaria prevention and control, first aid and emergency measure, maternal and child health, family planning, immunization, adolescent reproductive health, nutrition and treatment of common childhood diseases like diarrhea, pneumonia, malaria and severe malnutrition) given by health extension workers. In line with this, the households must also implement at least $75 \%$ and above of the packages listed above; and certified by districts health office for their achievement. Then, when respondents comply with the above conditions, it was scored in to yes otherwise into no. 


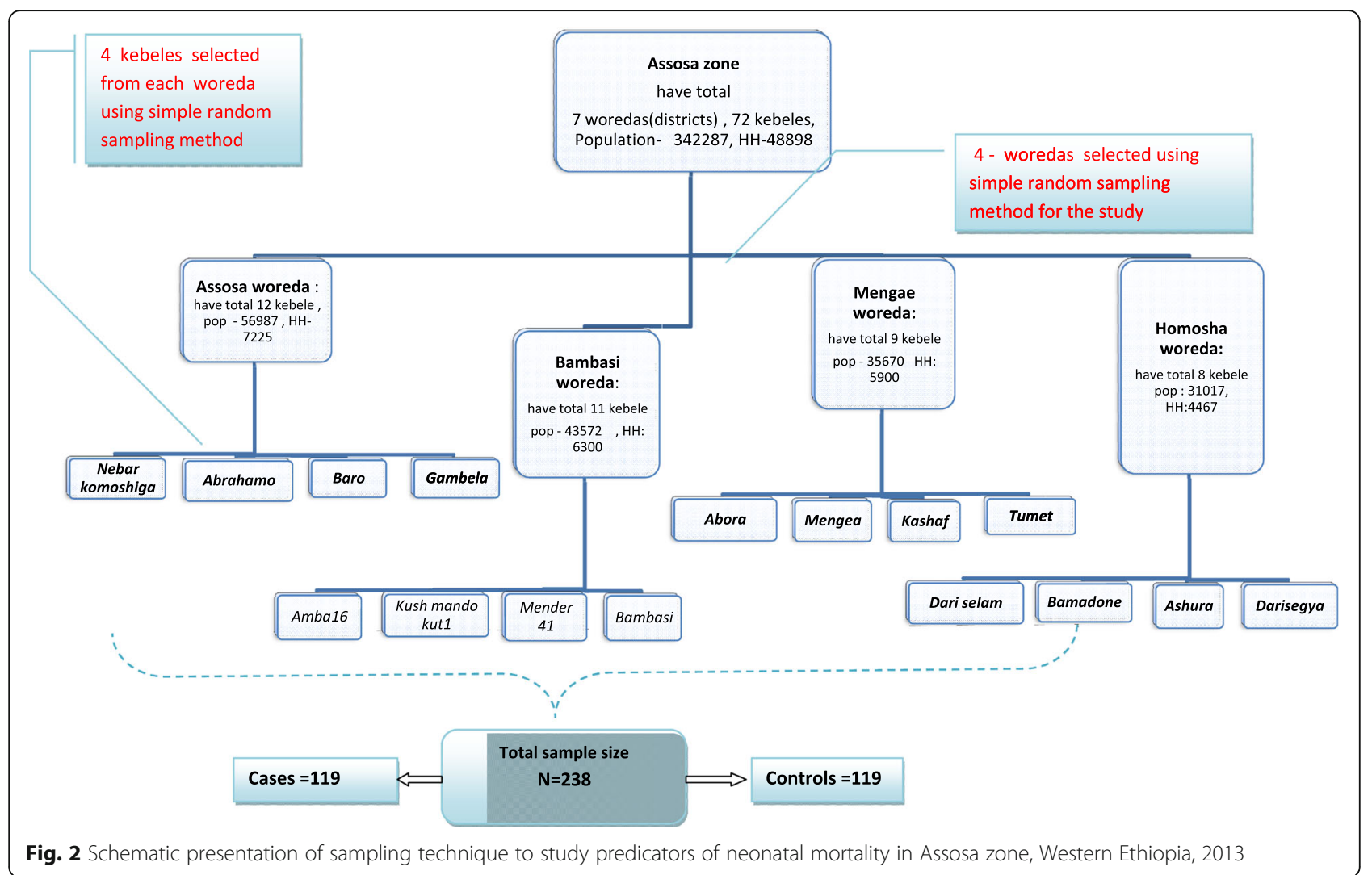

Pregnancy complication was measured based the following medical conditions during pregnancy period: vaginal bleeding, abdominal pain, persistence of back pain, blurry vision, no fetal movement and swelling of hands or face. Delivery complication was measured based on the following medical conditions during delivery time: mal presentation, obstructed labor, meconium stained amniotic fluid, premature rapture of membrane $(<1$ days), umbilical cord prolapsed, vaginal bleeding and retained placenta ( $>30 \mathrm{~min}$ ). For both delivery and pregnancy complication, the above medical conditions were predefined in the questionnaires. So mothers were responded from the predefined medical conditions; if they answered presence of at least one or more signs from the list, it was scored yes unless scored no.

Neonate size at birth was proxy indicator of birth weight at birth and measured by perception of the mother. It was labeled in to small and average size neonate. Small size neonates was proxy indicator of neonates with low birth weight $(<2500 \mathrm{~g})$ and average size neonates was proxy indicator of neonates with normal birth weight (2500-4200 g). Early initiation of breast-feeding was measured when the neonates start breast-feeding with in $1 \mathrm{~h}(=<1 \mathrm{~h})$ after birth and late initiation of breast-feeding when the neonates start breast-feeding $>=2 \mathrm{~h}$ after birth. Birth attendant was defined when mothers were assisted by health professionals (physicians, nurses, health officers, and health extensions trained in clean delivery) during delivery time, then it was labeled into skilled birth attendant otherwise labeled in to unskilled birth attendant. Structured interviewer administered questionnaire was used to collect information from each participants. Interview for the mothers were conducted face to face. Twelve diploma nurses, currently working on maternal and child health in health center and four bachelor sciences nurses currently working as health center -health post linkage focal person in health center; who speak and understand local language were recruited and trained as data collectors and supervisors respectively. Before data collection, the instrument was pretested in $5 \%$ of the total sample size. During data collection, the administered questionnaires were checked for completeness and consistency on daily basis by supervisors. After data collection completed, the principal investigator checked the data during data entry, cleaning, and analysis.

\section{Analysis}

Data was entered, processed, and analyzed using EPI Info version 7 and SPSS version 16 softwares (Additional file 1). Descriptive analysis was done, to check for outliers and inconsistencies. Then, univariate conditional logistic regression analysis was performed to identify candidates for multivariate conditional logistic regression. Strength of the association was measured using parameters of crude 
matched odd ratio (CmOR) with 95\% confidence interval (CI) and significance test at $P$ value $<0.05$. An inclusion criterion for multivariate conditional logistic regression was $\mathrm{P}$-value $<0.2$. Backward elimination strategy was used to build the final model and measure of association of each predictors were determined using parameter of adjusted matched odds ratio (AmOR) with 95\%CI. Statistical significance was tested using Wald statistical test at $\mathrm{P}$ value $<0.05$. In line with this, biologically meaningful interactions were assessed for inclusion in the final model. Furthermore, multicollinearity was checked using variance inflation factor (VIF) parameter, with acceptable range of 1-10 coefficients. Accordingly, collinearity was found between parity and gravidity; and diagnostic was made by removing gravidity from the model. Finally, goodness of fit of the final model was tested using likelihood ratio statistics and it was found fit.

\section{Results}

The preliminary data revealed that, from September 1, 2010 until September 1, 2013, 2075 neonates were born alive. Out of those live birth (LB) neonates, 139 singleton neonates were dead during the first 28 completed days after birth. As a result, NMR was 66.9 per 1000 LB. Totally 114 mothers of cases and 114 mothers of controls were included in the study, with $95.8 \%$ response rate. Among 114 cases, 27(23.68\%), 44(38.6\%), 43(37.72\%) died within first day, 2-7 days, 8-28 days respectively. The mean age of mothers of cases and controls were $30.3( \pm 6.85)$ and $30.1( \pm 4.89)$ respectively. The median household income was 800 birr for cases and 900 birr for controls. One hundred three mothers of cases (90.35\%) and 106 (92.98\%) mothers of controls were married. With regard to ethnicity, 84(73.68\%) mothers of cases, 82(71.93\%) mothers of control were Berta, and 24(21.05\%) mothers of cases and 25(21.93\%) mothers of control were Amhara. With regard to religion, ninety-one mothers of cases (79.82\%) and 90(78.95\%) mothers of controls were Muslim. Ninety-one mothers of cases (79.82\%) and seventy mothers of controls were illiterate (61.40\%) (Table 1).

During univariate analysis of socio demographic factors, Age of the mother $>=35$ years $[\mathrm{CmOR}=2.17$; 95\% CI: $1.16-4.04]$, illiterate mothers $[\mathrm{CmOR}=2.5$; $95 \%$ CI: $1.34-4.64]$, family size $>=5[\mathrm{CmOR}=1.19$; 95\%CI: 1.10-3.26], and model households (HHs) in health extension package (HEP) $[\mathrm{CmOR}=0.33$; 95\%CI: $0.18-0.58$ ] were found associated with NM at $5 \%$ level of significance. However, marital status, ethnicity, religion, occupation, type of roof of the house, presence of separate kitchen, type of water source, and presence of toilet facility were not significantly associated with NM (Table 1).

With regard to maternal biological and obstetric factors, age at first pregnancy $<20$ years old $[\mathrm{CmOR}=8.4$;
95\%CI: 3.32-21.23], gravidity of one $[\mathrm{CmOR}=4.31$; 95\% CI: 2.14-8.65] and gravidity of five and more [CmOR $=4.10$; 95\%CI: 1.77-9.47], parity of one [CmOR $=4.21 ; 95 \% \mathrm{CI}: 2.17-8.14 \mathrm{]}$ and parity of five and more $[\mathrm{CmOR}=3.99 ; 95 \% \mathrm{CI}: 1.52-10.44]$, previous history of still birth [CmOR $=3.00$; 95\%CI: 1.09-8.24]), ANC visit [CmOR $=0.30$; 95\%CI: 0.17-0.52], pregnancy complication $([\mathrm{CmOR}=3.00 ; 95 \% \mathrm{CI}: 1.67-5.38]$, delivery complication $[\mathrm{CmOR}=3.57 ; 95 \% \mathrm{CI}$ : $1.04-6.45]$, and birth interval with previous birth $<24$ months $[\mathrm{CmOR}=2.66$; 95\%CI: 1.04-6.81] were statistically significantly associated in the univariate analysis. Whereas, previous history of NM, previous history of abortion, mode of delivery, and tetanus toxoid (TT) vaccination were not statistically significantly associated (Table 2).

Neonatal factors, like small size neonate at birth $[\mathrm{CmOR}=5.00 ; 95 \% \mathrm{CI}: 2.44-10.22]$, gestational age $<37$ weeks $\quad[\mathrm{CmOR}=5.42 ; \quad 95 \% \mathrm{CI}: 2.42-12.15]$, partial breast-feeding $[\mathrm{CmOR}=3.55 ; 95 \% \mathrm{CI}$ : $1.69-7.44]$, and vaccination at birth $[\mathrm{CmOR}=0.35 ; 95 \% \mathrm{CI}$ : $1.19-0.66]$ were statistically significantly associated with NM in univariate analysis. Nevertheless, sex of the neonates and initiation time of breast-feeding were not statistically significantly associated (Table 3 ).

Concerning health service and delivery factors, home delivery $[\mathrm{CmOR}=2.30 ; 95 \% \mathrm{CI}: 1.36-3.88]$, postnatal care (PNC) $[\mathrm{CmOR}=0.13$; 95\%CI: $0.05-0.31]$ and unskilled birth attendant $[\mathrm{CmOR}=3.4 ; 95 \% \mathrm{CI}$ : $1.25-9.21]$ were statistically significantly associated with NM. Despite of the above, distance of health facility from home were not shown statistically significant association (Table 4).

From behavioral and psychosocial factors, only heavy work exercise during pregnancy $[\mathrm{CmOR}=2.41 ; 95 \% \mathrm{CI}$ : $1.37-4.24]$ was statistically significantly associated with NM in the univariate analysis. On the other hand, pregnancy planning, reaction of family to pregnancy, and domestic violence during pregnancy were not statistically significantly associated (Table 5).

In the multivariate conditional logistic regression analysis, model HHs in HEP, age at first pregnancy $<20$ years old, pregnancy complication, delivery complication, antenatal care visit, parity of one (primipara mothers), small size neonates at birth, gestational age $<$ 37 weeks, and home delivery were found statistically significantly associated with NM (Table 6).

Risk of $\mathrm{NM}$ was $68 \%$ lower $[\mathrm{AmOR}=0.32 ; 95 \% \mathrm{CI}$ : 0.12-0.86] in model HHs of HEP compared with those not model HHs in HEP.

Neonates born to mother's age at 1st pregnancy $<20$ years old were 4.3 times at higher risk of death [AmOR = 4.3; 95\% CI: 1.13-16.27] than those neonates born to mother's age at first pregnancy $>=20$. Neonates born to mothers who had complication during pregnancy were 
Table 1 Univariate association of socio demographic and socioeconomic factors and neonatal mortality in Assosa zone, Western Ethiopia, 2013

\begin{tabular}{|c|c|c|c|c|}
\hline Variables & $\begin{array}{l}\text { Case }(n=114) \\
\text { number }(\%)\end{array}$ & $\begin{array}{l}\text { Control }(n=114) \\
\text { number }(\%)\end{array}$ & $\mathrm{CmOR}(95 \% \mathrm{Cl})$ & $P$-value \\
\hline \multicolumn{5}{|l|}{ Age of the mother } \\
\hline$<20$ & $2(1.75)$ & $2(1.75)$ & $1.47(0.19-11.11)$ & 0.707 \\
\hline $20-34$ & $70(61.40)$ & $87(76.32)$ & 1 & \\
\hline$>=35$ & $42(36.84)$ & 25(21.93) & $2.17(1.16-4.04)$ & $0.014^{*}$ \\
\hline \multicolumn{5}{|l|}{ Marital status } \\
\hline Married & 103(90.35) & 106(92.98) & 1 & \\
\hline Widowed / Divorced & $11(9.65)$ & $8(7.02)$ & $1.42(0.54-3.75)$ & 0.469 \\
\hline \multicolumn{5}{|l|}{ Ethnicity } \\
\hline Berta & $84(73.68)$ & $82(71.93)$ & $1.17(0.39-3.39)$ & 0.769 \\
\hline Amhara & $24(21.05)$ & 25(21.93) & $1.10(0.32-3.74)$ & 0.871 \\
\hline Others & $6(5.26)$ & $7(6.14)$ & 1 & \\
\hline \multicolumn{5}{|l|}{ Religion } \\
\hline Muslim & $91(79.82)$ & $90(78.95)$ & $1.05(0.55-2.01)$ & 0.869 \\
\hline Christian & 23(20.18) & $24(21.05)$ & 1 & \\
\hline \multicolumn{5}{|l|}{ Educational status } \\
\hline Illiterate & $91(79.82)$ & $70(61.40)$ & $2.5(1.34-4.64)$ & $0.004^{*}$ \\
\hline Literate & $23(20.18)$ & $44(38.60)$ & 1 & \\
\hline \multicolumn{5}{|l|}{ Occupation } \\
\hline House wife & $48(42.11)$ & $58(50.88)$ & $0.96(0.38-2.43)$ & 0.945 \\
\hline Gold miner & $35(30.70)$ & $24(21.05)$ & $1.62(0.58-4.48)$ & 0.351 \\
\hline Farmer & $21(18.42)$ & $21(18.42)$ & $1.04(0.32-3.33)$ & 0.938 \\
\hline Others & $10(8.77)$ & $11(9.65)$ & 1 & \\
\hline \multicolumn{5}{|l|}{ Family size } \\
\hline$<5$ & $51(44.74)$ & $69(60.53)$ & 1 & \\
\hline$>=5$ & $63(55.26)$ & 45(39.47) & $1.90(1.10-3.26)$ & $0.020^{*}$ \\
\hline \multicolumn{5}{|l|}{ Monthly income } \\
\hline$<608$ birr & $32(28.07)$ & $21(18.42)$ & $1.68(0.90-3.13)$ & 0.097 \\
\hline$>=608$ birr & $82(71.93)$ & 93(81.58) & 1 & \\
\hline \multicolumn{5}{|l|}{ No of rooms } \\
\hline$<=2$ & $98(85.96)$ & $101(88.60)$ & $0.76(0.33-1.75)$ & 0.533 \\
\hline$>=3$ & $16(14.04)$ & 13(11.6) & 1 & \\
\hline \multicolumn{5}{|l|}{ Roof of the house } \\
\hline Corrugated iron sheet & $31(27.19)$ & $26(22.81)$ & 1 & \\
\hline Thatched & $83(72.81)$ & 88(77.19) & $0.76(0.39-1.46)$ & 0.412 \\
\hline \multicolumn{5}{|l|}{ Separate kitchen } \\
\hline Yes & $51(44.74)$ & $48(42.11)$ & $1.12(0.65-1.89)$ & 0.686 \\
\hline No & $63(55.26)$ & $66(57.89)$ & 1 & \\
\hline \multicolumn{5}{|l|}{ Water source } \\
\hline Safe & $92(80.70)$ & 100(87.72) & 1 & \\
\hline Unsafe & $22(19.30)$ & 14(12.28) & $1.61(0.80-3.22)$ & 0.174 \\
\hline \multicolumn{5}{|l|}{ Toilet facility } \\
\hline Yes & $82(71.93)$ & $92(80.7)$ & $0.62(0.34-1.15)$ & 0.135 \\
\hline
\end{tabular}


Table 1 Univariate association of socio demographic and socioeconomic factors and neonatal mortality in Assosa zone, Western Ethiopia, 2013 (Continued)

\begin{tabular}{llll}
\hline Variables & $\begin{array}{l}\text { Case }(n=114) \\
\text { number }(\%)\end{array}$ & $\begin{array}{l}\text { Control }(\mathrm{n}=114) \\
\text { number }(\%)\end{array}$ & CmOR(95\%Cl) \\
\hline No & $32(28.07)$ & $22(19.3)$ & 1 \\
Model HHs in HEP & & & \\
Yes & $35(30.70)$ & $67(58.77)$ & $0.33(0.18-0.58)$ \\
NO & $79(69.30)$ & $47(41.23)$ & 1 \\
\hline
\end{tabular}

*variables statistical significant at $\mathrm{p}$ value $<0.05$

CMOR: Crude matched Odds Ratio, HHs: House Holds, HEP - Health Extension package

4.59 times more likely at risk of death $[\mathrm{AmOR}=4.59 ; 95 \%$ CI: $1.53-13.78]$ compared with those neonates born to mothers who had no complication during pregnancy. Mothers who had complication during delivery were 2.8 fold at higher risk of having $\mathrm{NM}[\mathrm{AmOR}=2.80$; 95\% CI: 1.06-7.39] compared with those mothers who had no complication. Primipara mothers were 3.37 fold at higher risk of having neonatal death $[\mathrm{AmOR}=3.37$; 95\% CI: $1.05-10.78]$ than those mothers with parity of two to four. Neonates born to mothers who had received ANC were $66 \%$ lower risk of death $[\mathrm{AmOR}=0.34$; 95\% CI: $0.12-$ 0.94] compared with those neonates born to mothers who had not received ANC.

Neonates who were small size at birth were 3.4 times more likely at risk of death $[\mathrm{AmOR}=3.40 ; 95 \% \mathrm{CI}$ : 1.05-11.55] compared with those average size neonates at birth. In line with this, neonatal death was 4.35 times higher among neonates with gestational age $(\mathrm{GA})<37$ weeks $[\mathrm{AmOR}=4.35 ;$ 95\%CI: 1.16-16.28] compared with those neonates with GA $>=37$ weeks. Home delivered mothers were 2.8 times at higher risk of having neonatal death $[\mathrm{AmOR}=2.84 ; 95 \% \mathrm{CI}$ : $1.07-7.55]$ than those health institution delivered mothers.

\section{Discussion}

This study was conducted to identify predictors of neonatal mortality. It was employed community based matched case control design. This study revealed that, model HHs in HEP, age at first pregnancy $<20$ years old, pregnancy and delivery complication, ANC visit, parity of one (primipara mothers), small size neonates at birth, $\mathrm{GA}<37$ weeks, and home delivery were found to be predictors of NM.

Model HHs in HEP were significantly associated with neonatal mortality. Even though, there were no previous studies done specifically on association of model $\mathrm{HHs}$ in HEP and NM; previous reports by United Nations International Children's Fund and World Bank were indicated model HHs in HEP was major factor in decreasing child mortality in Ethiopia [14, 15]. This might be explained due to the fact that, model household families have better health awareness and practices through implementing the
16 health packages, that are directly and indirectly related with maternal and child health services. The packages comprise broad health services that can be implemented at home or health facilities, through improving healthseeking behavior of the mother during antenatal and postnatal periods. Thus, improvement of the health of the mothers and better caring for their newborn neonates might have significant effect for decreasing the risk of NM. On the other hand, maternal education, household income, and family size were not significantly associated with NM. This finding was similar with study finding from Ghana [13], but not consistent with studies done in Vietnam and Brazil $[19,20]$. This discrepancy might be probably because of small sample size of this study to detect small effect size measure. However, educational status of the mothers and income of the households could be clinically significantly associated.

Concerning maternal biological and obstetric factors, mother's age $<20$ years old at first pregnancy was shown statistically significant association with NM. This finding was congruent with previous studies $[17,18,20]$. This could be explained due to the fact that, early age pregnant mothers might not physically and psychologically ready to have child; have less awareness and knowledge on pregnancy and new born care. Hence, those all could have negative effect on health seeking behavior of the mother for ANC and PNC services. Consequently, this might made them susceptible to have high risk of pregnancy and delivery complications, risk of having preterm birth, and LBW neonates; which are known risk factors for NM. Pregnancy and delivery complication were significantly associated with NM. This finding was supported by previous studies [17, 21-24]. This is a known fact that, neonates born to mothers who had pregnancy complications were at higher risk of having neonatal death because mothers might be exposed to higher risk of nutritional problems, having high probability of preterm birth, and LBW neonates. In line with this, mothers who have delivery complication could have high probability of risk of neonatal death, due to the fact neonates may have high risk of having sepsis, birth asphyxia, congenital malformation, and birth trauma, which are 
Table 2 Univariate association of maternal biological and obstetric factors and neonatal mortality, in Assosa zone, Western Ethiopia, 2013

\begin{tabular}{|c|c|c|c|c|}
\hline Variables & $\begin{array}{l}\text { Case }(n=114) \\
\text { number(\%) }\end{array}$ & $\begin{array}{l}\text { Control( }(n=114) \\
\text { number }(\%)\end{array}$ & $\mathrm{CmOR}(95 \% \mathrm{Cl})$ & $P$-value \\
\hline \multicolumn{5}{|c|}{ Delivery complication } \\
\hline Yes & $70(61.40)$ & $34(29.82)$ & $3.57(1.97-6.45)$ & $0.004^{*}$ \\
\hline No & $44(38.0)$ & 80(70.18) & 1 & \\
\hline \multicolumn{5}{|c|}{ Age at first pregnancy } \\
\hline$<20$ & $46(40.35)$ & $9(7.89)$ & $8.40(3.32-21.23)$ & $<0.001^{*}$ \\
\hline$>=20$ & $68(59.65)$ & 105(92.11) & 1 & \\
\hline \multicolumn{5}{|l|}{ Parity } \\
\hline । & $59(51.75)$ & $28(24.56)$ & $4.21(2.17-8.14)$ & $<0.001^{*}$ \\
\hline$\|-I V$ & 38(33.33) & 79(69.30) & 1 & \\
\hline$V_{+}$ & 18(18.42) & $7(6.14)$ & $3.99(1.52-10.44)$ & $0.004^{*}$ \\
\hline \multicolumn{5}{|l|}{ Gravidity } \\
\hline । & $51(44.74)$ & $24(21.05)$ & $4.31(2.14-8.65)$ & $<0.001^{*}$ \\
\hline II-IV & $39(34.21)$ & $81(71.05)$ & 1 & \\
\hline$V_{+}$ & $24(21.05)$ & $9(7.89)$ & $4.10(1.77-9.47)$ & $0.001^{*}$ \\
\hline \multicolumn{5}{|c|}{ Birth interval with previous birth } \\
\hline$<24$ months & $50(84.75)$ & $45(38.46)$ & $2.66(1.04-6.81)$ & $0.033^{*}$ \\
\hline$>=24$ month & $9(15.25)$ & $44(49.44)$ & 1 & \\
\hline \multicolumn{5}{|c|}{ Previous history of still birth } \\
\hline Yes & 16(14.04) & $6(5.26)$ & $3.00(1.09-8.24)$ & $0.025^{*}$ \\
\hline No & $98(85.96)$ & 108(94.74) & 1 & \\
\hline \multicolumn{5}{|c|}{ Previous history of abortion } \\
\hline Yes & $1(0.88)$ & $2(1.75)$ & $0.50(0.05-5.51)$ & 0.571 \\
\hline No & 113(99.12) & 112(98.25) & 1 & \\
\hline \multicolumn{5}{|c|}{ Previous history of NM } \\
\hline Yes & 13(11.40) & $5(4.39)$ & $3.00(0.97-9.29)$ & 0.0578 \\
\hline No & $101(88.6)$ & 109(95.61) & 1 & \\
\hline \multicolumn{5}{|l|}{ ANC visit } \\
\hline Yes & $47(41.23)$ & $84(73.68)$ & $0.30(0.17-0.52)$ & $<0.001^{*}$ \\
\hline No & $67(58.77)$ & $30(26.32)$ & 1 & \\
\hline \multicolumn{5}{|l|}{$\Pi \pi$ dose received } \\
\hline$<2$ & $9(7.89)$ & $5(4.39)$ & $3.00(0.60-14.60)$ & 0.178 \\
\hline 2 to5 & 105(92.11) & 109(95.61) & 1 & \\
\hline \multicolumn{5}{|c|}{ Pregnancy complication } \\
\hline Yes & $56(49.12)$ & $26(22.81)$ & $3.00(1.67-5.38)$ & $<0.001^{*}$ \\
\hline No & $58(50.88)$ & $88(77.19)$ & 1 & \\
\hline
\end{tabular}

*Variables statistically significant at $P$ value $<0.05, A N C$ : antenatal care, $\Pi$ : tetanus toxoid, $N M$ : neonatal mortality

known cause of NM. Primipara mothers had shown higher risk of having neonatal death. This finding was confirmed by findings of previous studies [13, 21, 23]. This could be explained due to the fact that, primipara mothers might have poor knowledge and skills about newborn care (such as exclusive breast-feeding practice, early initiation of breast-feeding and kangaroo care for new born). In line with this, they may have poor awareness to seek medical care during antenatal and postnatal period. Neonates born to mothers who had received ANC were statistically significantly associated with decreasing risk of neonatal death. This finding was in agreement with findings of previous studies done in Egypt, Vietnam, Kenya, and Brazil [18, 19, 21, 24]. This 
Table 3 Univariate association of neonatal related factors and neonatal mortality in Assosa zone, Western Ethiopia, 2013

\begin{tabular}{|c|c|c|c|c|}
\hline & Case $(n=114)$ & Control $(n=114)$ & & \\
\hline Variables & number(\%) & number(\%) & $\mathrm{CmOR}(95 \% \mathrm{Cl})$ & $P$ value \\
\hline \multicolumn{5}{|l|}{ Sex of the neonate } \\
\hline Male & $57(50)$ & $56(49.12)$ & $1.03(0.66-1.75)$ & 0.892 \\
\hline Female & $57(50)$ & $58(50.88)$ & 1 & \\
\hline \multicolumn{5}{|c|}{ Size of neonates at birth } \\
\hline Average size & $61(53.51)$ & 97(85.09) & 1 & \\
\hline Small size & $53(46.49)$ & 17(14.91) & $5.00(2.44-10.22)$ & $<0.001^{*}$ \\
\hline \multicolumn{5}{|l|}{ Gestational age } \\
\hline$>=37$ weeks & $70(61.40)$ & $101(88.60)$ & 1 & \\
\hline$<37$ weeks & $44(38.60)$ & 13(11.40) & $5.42(2.42-12.15)$ & $<0.001^{*}$ \\
\hline \multicolumn{5}{|c|}{ Time of breast feeding initiation } \\
\hline$<=1 \mathrm{~h}$ (early) & $19(21.84)$ & 25(21.93) & 1 & \\
\hline$>=2-24 \mathrm{~h}$ (late) & 68(78.16) & 89(78.07) & $1.13(0.56-2.26)$ & 0.723 \\
\hline \multicolumn{5}{|c|}{ Breast feeding practice } \\
\hline Exclusive & 14(16.09) & $51(44.74)$ & 1 & \\
\hline Partial & $73(83.91)$ & $63(55.26)$ & $3.55(1.69-7.44)$ & $<0.001^{*}$ \\
\hline \multicolumn{5}{|l|}{ Vaccination at birth } \\
\hline Yes & $32(28.07)$ & $57(50)$ & $0.35(0.19-0.66)$ & $0.001^{*}$ \\
\hline No & $82(71.93)$ & $57(50)$ & 1 & \\
\hline
\end{tabular}

*Variables statistically significant at $\mathrm{P}$ - value $<0.05$

Table 4 Univariate association of delivery and health service related factors and neonatal mortality in Assosa zone, Western Ethiopia, 2013

\begin{tabular}{|c|c|c|c|c|}
\hline Variables & $\begin{array}{l}\text { Case }(n=114) \\
\text { number(\%) }\end{array}$ & $\begin{array}{l}\text { Control }(n=114) \\
\text { number }(\%)\end{array}$ & $\mathrm{CmOR}(95 \% \mathrm{Cl})$ & $P$-value \\
\hline \multicolumn{5}{|c|}{ Place of delivery } \\
\hline Home & $76(66.67)$ & $50(43.86)$ & $2.3(1.36-3.88)$ & $0.001^{*}$ \\
\hline HF & 38(33.33) & $64(56.14)$ & 1 & \\
\hline \multicolumn{5}{|c|}{ Distance of HF from home } \\
\hline$<=2 \mathrm{~h}$ & 105(92.11) & 108(94.74) & 1 & \\
\hline$>2 \mathrm{~h}$ & $9(7.89)$ & $6(5.26)$ & $1.5(0.53-4.21)$ & 0.443 \\
\hline \multicolumn{5}{|c|}{ Delivery attendants } \\
\hline Skilled & $31(40.79)$ & $37(74)$ & 1 & \\
\hline Unskilled & $45(59.21)$ & $13(26)$ & $3.40(1.25-9.21)$ & $0.016^{*}$ \\
\hline \multicolumn{5}{|c|}{ Mode of delivery } \\
\hline Vaginal & 103(90.35) & 107(93.86) & 1 & \\
\hline C-section & $11(9.65)$ & $7(6.14)$ & $1.5(0.53-4.21)$ & 0.441 \\
\hline \multicolumn{5}{|l|}{ PNC visit } \\
\hline Yes & $64(56.14)$ & 102(89.47) & $0.13(0.05-0.31)$ & $<0.001^{*}$ \\
\hline No & $50(43.86)$ & $12(10.53)$ & 1 & \\
\hline
\end{tabular}

was probably receiving ANC could improve nutritional status of the mother, receiving iron and folic acid, TT immunization, and early detection of complications during pregnancy, consequently those could contribute to have low risk of NM. However, birth space with previous birth $<24$ months, previous history of stillbirth, previous history of NM, and TT vaccination were not statistically

Table 5 Univariate association of behavioral and psychosocial related factors and neonatal mortality in Assosa zone, Western Ethiopia, 2013

\begin{tabular}{|c|c|c|c|c|}
\hline Variables & $\begin{array}{l}\text { Case }(n=114) \\
\text { number (\%) }\end{array}$ & $\begin{array}{l}\text { Control }(n=114) \\
\text { number }(\%)\end{array}$ & CmOR(95\%Cl) & $P$ value \\
\hline \multicolumn{5}{|c|}{ Pregnancy planning } \\
\hline Planned & $65(57.02)$ & $79(69.30)$ & $0.61(0.35-1.03)$ & 0.068 \\
\hline Un Planned & 49(42.98) & $35(30.70)$ & 1 & \\
\hline \multicolumn{5}{|c|}{ Reaction of family to pregnancy } \\
\hline Happy & 103(90.35) & 106(92.98) & 1 & \\
\hline Not happy & $11(9.65)$ & $8(7.02)$ & $1.37(0.55-3.41)$ & 0.493 \\
\hline \multicolumn{5}{|c|}{ Domestic violence during pregnancy } \\
\hline Yes & 13(11.40) & $11(9.65)$ & $1.18(0.52-2.63)$ & 0.683 \\
\hline No & $101(88.60)$ & 103(90.35) & 1 & \\
\hline \multicolumn{5}{|c|}{ Heavy work exercise during pregnancy } \\
\hline Yes & $54(47.37)$ & $30(26.32)$ & $2.41(1.37-4.24)$ & $0.002^{*}$ \\
\hline No & $60(52.3)$ & $84(73.68)$ & 1 & \\
\hline
\end{tabular}

*Variables statistically significant at $\mathrm{P}$-value $<0.05$ 
Table 6 Multivariate analysis of selected explanatory factors and neonatal mortality in Assosa zone, Western Ethiopia, 2013

\begin{tabular}{ll}
\hline Variables & AmOR(95\%Cl) \\
\hline Age of the mother & \\
$<20$ & $0.14(0.01-2.22)$ \\
$20-34$ & 1 \\
$>=35$ & $1.87(0.72-4.85)$ \\
Educational status & \\
Illiterate & $2.59(0.87-7.65)$ \\
Literate & 1 \\
Family size & \\
$<5$ & 1 \\
$>=5$ & $1.53(0.64-3.65)$ \\
Monthly income & \\
$<608$ birr & $0.45(0.18-1.09)$ \\
$>=608$ birr & 1 \\
Model HHs in HEP & \\
Yes & $0.32(0.12-0.86)$ \\
No & 1 \\
Water type & $1.00(0.37-2.67)$ \\
Safe & \\
Unsafe & \\
Toilet Facility & \\
Yes &
\end{tabular}

Age at 1st pregnancy

$$
\begin{aligned}
& <20 \\
& >=20
\end{aligned}
$$$$
4.30(1.13-16.27)
$$$$
1
$$

Pregnancy complication

Yes

Delivery complication

$\begin{array}{ll}\text { Yes } & 2.80(1.06-7.39) \\ \text { No } & 1 \\ \text { Parity } & \\ \text { I } & 3.37(1.05-10.78) \\ \text { II-IV } & 1 \\ \text { V+ } & 1.67(0.34-8.38)\end{array}$

Birth interval with previous birth

$$
\begin{array}{ll}
<24 \text { months } & 4.02(0.59-27.42) \\
>=24 \text { month } & 1 \\
\text { Previous history of still birth } & \\
\text { Yes } & 3.4(0.50-23.86) \\
\text { No } & 1
\end{array}
$$

Previous history of NM $P$-value

0.161

0.193

0.553

0.335

0.078

$0.024^{*}$

0.518

$0.031^{*}$

$0.006^{*}$

$0.037^{*}$

$0.041^{*}$

0.527

0.154

0.203 dose received

$<2$

2-5

0.25(0.01-13.43)

0.498

Size of neonates at birth

Average
Small

3.40(1.05-11.55)

$0.049^{*}$

Type of breast feeding practice

Exclusive

Partial

2.06(0.14-13.23)

0.597

Vaccination at birth

Yes

0.56(0.16-2.09)

No

1

Gestational age

$<37$-Week

4.35(1.16-16-28)

$0.029^{*}$

$>=37$ Week

1

Place of delivery

Home

2.84(1.07-7.55)

$0.035^{*}$

HF

Delivery attendants

Skilled

Unskilled

$2.00(0.79-5.02)$

0.139

PNC visit

Yes

$0.31(0.04-2.68)$

No

1

Heavy work exercise during pregnancy

Yes

2.35(0.93-5.92)

No

Pregnancy planning

Planned

$0.67(0.27-1.66)$

0.339

Unplanned

*Independent predictor variables, statistically significant at $\mathrm{P}$-value $<0.05$

significantly associated. This finding was not consistent with previous studies $[18,24,25]$. This disagreement might be due to homogeneous distribution of the risk factors (previous history of stillbirth, previous history of $\mathrm{NM}$, and TT vaccination) in both comparable groups, as well as small sample size of the study. Despite of the above non-statistical significance, birth space with 
previous birth $<24$ month could be clinically significantly associated.

Among the neonatal related factors, small size neonates were at higher risk of death than those average size neonates were. This finding was similar with previous studies conducted in Kenya, Ethiopia, Nigeria, and Indonesia [21, 26-28]. This might be small size neonates were highly susceptible for different infections due to having low immunity defense. Neonatal death was statistically higher among neonates with $\mathrm{GA}<37$ weeks. This result was in line with results of previous studies [21, 24]. This is a well-known fact that, neonates born with GA $<37$ weeks are exposed to many physiologic challenges and fatal conditions to adapt the extra uterine life; such as hypothermia, respiratory distress, different cardio vascular and hematological conditions, like anemia and hyperbilirubinemia. In line with this, immature immune defense can also expose them to infections, nutritional deficiencies, gastro intestinal problems, and electrolyte imbalance. Nevertheless, breastfeeding practice and vaccination at birth were not shown significant association. This finding was similar with previous study from Kenya [26], however, study from Indonesia was revealed significant association [28]. Vaccination at birth was not statistically significantly associated; vaccination at birth might not have immediate clinical significance during the neonatal period. On the other hand, majority of the neonates in both comparable groups were partial breast-fed, this could lead to statistically non-significance association. However, clinically this could be significantly associated.

Concerning health service and delivery related factors; neonatal death was statistically significantly higher among neonates born to home delivered mothers. This finding was in line with findings from previous studies done in Ethiopia and Vietnam [33, 34]. Neonates born to home delivered mothers are highly exposed to different infections and birth traumas, due to absence of safe and clean delivery kits, professional birth attendant, and essential newborn care practices especially during the first hour immediately after birth;this could increase risk of death. However, mode of delivery, PNC, and unskilled birth attendant were not statistically significantly associated with NM. Finding of this study about mode of delivery was similar with findings of previous studies $[29,30]$, but finding about unskilled birth attendant and PNC were not consistent with previous study [16]. This disagreement might be due small sample size of this study to detect small effect size measure of both explanatory factors. In addition, distribution of type of birth attendant was homogenous in both comparable groups. Although both factors were not statistically significant in this study, clinically could be significantly associated.

Concerning physical and psychological factors, heavy work exercise and pregnancy planning were not statistically significantly associated with risk of neonatal death. Conversely, previous studies reported statistically significant association [35, 36]. This discrepancies could be due to mothers who were reported they had heavy work exercise and violence during pregnancy period were very few and similar distribution in both comparable groups.

Generally, based on the findings of this study, EDHS report, and general situation of the region; there were three suggested reasons for increasing NMR in the region, while the national NMR was decreased between 2005 and 2011. Firstly, health services coverage of the region (model HHs in HEP, $\mathrm{ANC}, \mathrm{PNC}$, and institutional delivery) were very low compared with health services coverage of the rest regions in the country. Secondly, poor access and utilization of basic emergency obstetric care, and intensive newborn care centers in the region. The third reasons were, early marriage and early pregnancy, and home delivery were wide spread cultural practice in the region. Even though, the rate of $\mathrm{NM}$ of the region was increased between 2005 and 2011, it had no effect on the national NMR for the same period; due to small population proportion of the region compared with other regions in country.

\section{Study strengths and limitations}

At last, it is crucial to discuss strengths as well as limitations of this study. The study employed matched case control design, subsequently this could improve efficiency to control cofounders by increasing precision of effect size estimate. Moreover, this study was community based; hence, it gave an opportunity to investigate risk factors present within the community.

Despite the above strengths, the study also had limitations. Firstly, majority of the data was three-year recall period self reported data by mothers. Hence, this might introduced recall bias due to differential recall of information among mothers of cases and mothers of controls; this may lead to differential misclassification of study subjects and finally distortion of effect size estimates in any direction from null. Secondly, majority of the socio demographic factors were temporal measurements but taken as proxy indicators of the past and this might not give true measurement of the past. The third limitation was, small size and average size neonates was proxy indicator of birth weight of neonates, due to absence of birth weight record and this might not be accurate measurement. Lastly, nutritional status of the mothers and delivery related factors (type of cord cutting and tie materials, delivery surfaces) were not studied in detail. Therefore, the reader of this article should consider those limitations might have implication on internal validity of the result. 


\section{Clinical implications}

Based on the findings of this study, improving coverage of model HHs in HEP will have broad impact to reduce neonatal mortality, since it comprise many health packages directly and indirectly related to maternal and new born health, that are crucial to implement at family level. Secondly, improving access and utilization of basic emergency obstetric and intensive newborn care service to reduce risk of delivery complications and improve newborn survival especially for preterm and LBW neonates respectively. The third interventions are promotion of ANC, institutional delivery, health education and family planning for adolescents to prevent early age pregnancy. Generally, those interventions should be implemented at community level to avert the high neonatal mortality in the region.

\section{Future research}

Nutritional status of the mother and delivery related risk factors, such as: cord cutting material, delivery surface, and cord tie material used during delivery were not investigated in detail and should be studied in future.

\section{Conclusions}

In summary, model households in health extension packages, mothers age at first pregnancy $<20$ years old, complication during pregnancy, complication during delivery, primipara mothers, antenatal care visit, small size neonates at birth, gestational age $<37$ weeks, and home delivery were found as independent predictors of neonatal death. Therefore, promotion of model $\mathrm{HH}$ in HEPs, ANC visit, institutional delivery, and prevention of early age pregnancy and improve access of basic emergency obstetric care and intensive newborn care are very crucial interventions to avert the high risk of neonatal mortality.

\section{Additional files}

Additional file 1: Anonymous data generated and analyzed to study predictors of neonatal mortality in Assosa Zone, Western Ethiopia, 2013. (XLSX $99 \mathrm{~kb})$

\footnotetext{
Abbreviations

AmOR: Adjusted matched Odd Ratio; ANC: Anti Natal Care; Cl: Confidence Interval; CmOR: Crude matched Odd Ratio; EDHS: Ethiopian Demographic Health Survey; GA: Gestational Age; HEP: Health Extension Package; HF: Health Facility; HHs: Households; LBW: Low Birth Weight; MDG: Millennium Development Goal; NM: Neonatal Mortality; NMR: Neonatal Mortality Rate; PNC: Post Natal Care; SPSS: Statistical Package for Social Science; TT: Tetanus Toxoid; VIF: Variance Inflation Factor; WHO: World Health Organization
}

\section{Acknowledgements}

We would like to thank Benshangul Gumuze Regional Health Bureau for their financial support. We are also grateful to Jimma University, College of Public Health and Medical Science for their support and facilitation to conduct the study on time. Our gratitude extends to Assosa zone health extension workers for their cooperation to make the child health registration book accessible for preliminary data collection.

\section{Funding}

This article presents independent research, funded by Benshangul Gumuze Regional Health Bureau under its program to support child health program with applied research. The views, expressed in this article were those of authors and not necessarily of the funder.

\section{Availability of data and materials}

All data generated or analyzed during this study are included in this manuscript [Additional file 1].

\section{Authors' contributions}

FK was responsible from conception to design, acquisition of data, analysis, interpretation, drafting and revising the manuscript for submission. KW involved from inception to design, interpretation, and review the manuscript for intellectual content. DH participated in the inception to design, analysis, interpretation, and edits the manuscript for final submission. All authors read and approved the final manuscript.

\section{Authors' information}

${ }^{1} \mathrm{MPH}$ in Epidemiology, Field Epidemiologist, STOP polio program, Port Moresby, Papua New Guinea. ${ }^{2}$ Professor of Epidemiology, director of Africa resilience innovation lab, principal investigator, and monitoring and evaluation training program focal person, Department of Epidemiology, College of Public Health and Medical Science, Jimma University, Jimma, Ethiopia. ${ }^{2}$ Assistant Professor of Epidemiology, Department of Epidemiology, College of Public Health and Medical Science, Jimma University, Jimma, Ethiopia.

\section{Ethics approval and consent to participate}

Ethical clearance was obtained from Jimma University, College of Public Health and Medical Science research ethical board (Ref.No. PPGC/226/2073). Consent was sought and obtained from all study participants using consent form attached with questionnaires before conducting the interview. Moreover, permission was also offered from Benshangul Gumuze Regional Health Bureau to conduct the study in the selected study area.

\section{Consent for publication}

Not applicable.

\section{Competing interests}

The authors declare that they have no competing interests.

\section{Publisher's Note}

Springer Nature remains neutral with regard to jurisdictional claims in published maps and institutional affiliations.

\section{Author details \\ ${ }^{1}$ Department of Disease Prevention and Health Promotion, Benshangul Gumuze Regional Health Bureau, Assosa, Ethiopia. ${ }^{2}$ Department of Epidemiology, Colleage of Public Health and Medical Science, Jimma University, Jimma, Ethiopia.}

Received: 31 May 2018 Accepted: 13 March 2019

Published online: 29 March 2019

References

1. World Health Statistics. Indicator compendium. Geneva, Switzerland: World Health Organization; 2013. https://www.who.int/gho/publications/world./ WHS2013_indicatorcompendium.pdf.

2. Rajaratnam JK, Marcus JR, Flaxman AD, Wang $H$, Levin- Rector $A$, et al. Neonatal, post neonatal, childhood, and under-5 mortality for 187 countries, 1970_2010: a systematic analysis of progress towards Millennium Development Goal 4. Lancet. 2010;375(9730):1988-2008. https://doi.org/10. 1016/S0140-6736(10)60703-9 PMID:20546887 [Indexed for MEDLINE].

3. UN Inter agency Group for Child Mortality Estimation (IGME). Levels and trends in child Mortality. UN Plaza, New York, NY 10017, USA: UNICEF, 2012; 2012. http://www.who.int/maternal_child_adolescent/documents/levels trends_child_mortality_2012/en/. 
4. UNICEF. Committing to Child Survival. In: A promise renewed. Progress report 2012. United Nations plaza, New York, NY 10017, USA: UNICEF Division of Policy and Strategy; 2012. https://www.unicef.org/eapro/A_ Promise_Renewed_Report_2012.pdf.

5. Lawn JE, Cousens S, Zupan J . 4 million neonatal deaths: when? Where? Why? Lancet. 2005; 365(9462):891-900.DOl:https://doi.org/10.1016/S01406736(05)71048-5. PMID:15752534 [Indexed for MEDLINE]

6. CSA \& ORC. Ethiopia Demographic and health Survey 2011. Addis-Ababa, Ethiopia and Calverton, Maryland, USA: Central Statistics Authority \& OCR Macro; 2012.

7. CSA \& ORC. Ethiopia Demographic and health Survey 2005. Addis-Ababa, Ethiopia and Calverton, Maryland, USA: Central Statistics Authority \& OCR Macro; 2006

8. Gumuze B. Regional health bureau annual HMIS report. Assosa: Ethiopia; 2013.

9. Mosley $\mathrm{WH}$, Chen LC. Analytical frame work for study of child survival in developing countries: strategies for research. Pop Dev Rev. 1984;(supp (10)): 25-45. http://www.jstor.org/stable/2807954. https://doi.org/10.2307/2807954.

10. Lawn JE, Kinney MV, Black RE, Pitt C, Cousens S, etal KK. Newborn survival: a multi-country analysis of a decade of change. Health Policy Plan. 2012;(supp/ 3):iii6-28. https://doi.org/10.1093/heapol/czs053 PMID:22692417 [Indexed for MEDLINE].

11. Mengistu H. Addressing Newborn Death to Reach Ethiopia's MDG 4. Addis Ababa: Ethiopia: FederalMinistryofHealth; 2012. https://wfpha.confex.com/ wfpha/2012/webprogram/Session1832.html

12. Rahman S, Salameh K, Bener A, El Ansar W. Socioeconomic associations of improved maternal, neonatal, and perinatal survival in Qatar. Int J of Women's Health. 2010;2:311-8. https://doi.org/10.2147/IJWH.S12426 PMID: 21151678 [Indexed for MEDLINE].

13. Welaga P, Moyer CA, Aborigo R, Adongo P, Williams J, et al. Why are babies dying in the first month after birth? A 7 -year study of neonatal mortality in northern Ghana. PLoS One. 2013;8(3):e58924. https://doi.org/10.1371/journal. pone.0058924

14. UNICEF. Survival and Health Briefing Note, 2013. Addis Ababa: Ethiopia: UNICEF Media and External Relations Section; 2013. www.unicef.org/ ethiopia/

15. Nesanet W, Gandham NV. The health extension program in Ethiopia, 2013 Washington, DC: World Bank, UNICO Studies Series; No. 10, 2013. "UR https://openknowledge.worldbank.org/handle/1086/12280.

16. Mercer A, Haseen F, Huq NL, Uddin N, Hossain Khan Metal M. Risk factors for neonatal mortality in rural areas of Bangladesh served by a large NGO program. Health Policy Plan. 2006;21(6):432-43. https://doi.org/10.1093/ heapol/czl024. PMID: 16943220 [Indexed for MEDLINE].

17. Upadhyay RP, Dwivedi PR, Rai SK, Misra P, Kalaivani M. Determinants of neonatal mortality in rural Haryana: a retrospective population based study. Indian Pediatr. 2012:49(4):291-4 PMID: 21992859 [Indexed for MEDLINE].

18. Hassan MH, Ahmed MR, Shhata SF, Sadek S. Risk factors of perinatal and neonatal mortality in Alexandria, Egypt. J Egypt Public Health Assoc. 2012; 87(3-4):51-66. https://doi.org/10.1097/01.EPX.0000417960.79703.06. PMID: 22936240.[Indexed for MEDLINE].

19. Målqvist M, Nga NT, Eriksson L, Wallin L, Hoa DP. Ethnic inequity in neonatal survival: a case-referent study in northern Vietnam. Acta Paediatr. 2011; 100(3):340-6. https://doi.org/10.1111/j.1651-2227.2010.02065.x. PMID: 20958789 [Indexed for MEDLINE]

20. Oliveira EF, Gama SG, Silva CM. Teenage pregnancy and other risk factors for fetal and infant mortality in the city of Rio de Janeiro, Brazil. Cad Saude Publica. 2010;26(3):567-78 PMID: 20464075 [Indexed for MEDLINE].

21. Yego F, Stewart Williams J, Byles J, Nyongesa P, Aruasa W. A retrospective analysis of maternal and neonatal mortality at a teaching and referral hospital in Kenya. Reprod Health. 2013;10:13. https://doi.org/10.1186/17424755-10-13. PMID: 23421605 [Indexed for MEDLINE].

22. Kalu CA, Umeora OU. Risk factors and perinatal outcome of umbilical cord prolapse in Ebonyi State University teaching hospital, Abakaliki, Nigeria. Niger J Clin Pract. 2011;14(4):413-7. https://doi.org/10.4103/1119-3077. 91746. PMID: 22248940 [Indexed for MEDLINE]

23. Ronel D, Wiznitzer A, Sergienko R, Zlotnik A, Sheiner E. Trends, risk factors and pregnancy outcome in women with uterine rupture. Arch Gynecol Obstet. 2012;285(2):317-21. https://doi.org/10.1007/s00404-011-1977-8. PMID: 21735183[Indexed for MEDLINE].
24. Nascimento RM, Leite AJ, Almeida NM, Almeida PC, Silva CF. Determinants of neonatal mortality: a case-control study in Fortaleza, Ceará state, Brazil. Cad Saude Publica. 2012;28(3):559-72. PMID: 22415188 [Indexed for MEDLINE].

25. Kozuki N, Lee A, Silveria M, Victoria C, Adair L, Humphrey J, et al. Association of birth interval with small for gestational age, preterm, and neonatal and infant mortality : a meta analysis. BMC Public Health. 2013;13(suppl 3):S3 https://doi.org/10.1186/1471-2458-13-S3-S3.

26. Salihu HM, August EM, D La Cruze C, Mogus MF, Weldeselasse H, Alio AP, et al. Infant mortality and risk of small size for gestational age in subsequent pregnancy : retrospective cohort study. Maternal and Child Health J. 2013; 17(6):1044-51. https://doi.org/10.1007/s10995-012-1085-9 PMID: 22833336 [Indexed for MEDLINE].

27. Onwuanaku CA, Okolo SN, Lge KO, Okpe SE, Toma BO. The effects of birth weight and gender on neonatal mortality in north Central Nigeria. BMC Research Note. 2011;4:562. https://doi.org/10.1186/1756-0500-4-562.

28. Sutan $\mathrm{R}$, Berkat $\mathrm{S}$. Does cultural practice affects neonatal survival- a case control study among low birth weight babies in Aceh Province, Indonesia. BMC Pregnancy Childbirth. 2014;14:342. https://doi.org/10.1186/1471-239314-342. PMID: 25269390 [Indexed for MEDLINE].

29. Imtiaz J, Hillary H, Sohail S, Amna Z, Naushaba M. Neonatal mortality, risk factors, and causes: a prospective population-based cohort study in urban Pakistan. Bull World Health Organ. 2009:87:130-8. https://doi.org/10.2471/ BLT.08.050963.

30. Zhu JJ, Bao YY, Zhang GL, Ma LX, Wu MY. No relationship between mode of delivery and neonatal mortality and neurodevelopment in very low birth weight infants aged two years. World J Pediatr. 2012;10(3):227-31. https:// doi.org/10.1007/s12519-014-0497-6. PMID: 25124973 [Indexed for MEDLINE].

31. Salihu HM, Bowen CM, Wilson RE, Marty PJ. The impact of previous cesarean section on the success of future fetal rogramming pattern. Arch Gynecol Obstet. 2011;284(2):319-26. https://doi.org/10.1007/s00404-010-1665-0. PMID: 20821225 [Indexed for MEDLINE].

32. Lohela TJ, Campbell R, Gabrysch S. Distance to care, facility delivery and early neonatal mortality in Malawi and Zambia. PLoS One. 2012;7(12):e52110. https://doi.org/10.1371/journal.pone.0052110.

33. Tura G, Fantahun M, Worku A. The effect of health facility delivery on neonatal mortality: systematic review and meta-analysis. BMC Pregnancy and Childbirth. 2013;13(18). http://www.biomedcentral.com/1471-2393/13/18. https://doi.org/10.1186/1471-2393-13-18.

34. Malquist M. Who can save the unseen? Neonatal mortality in Quang Nine,Vietnam. Digital comprehensive summaries, vol. 587: Department of Women and Children's Health, Uppsala University; 2010. p. 74. ISBN 978-91-554

35. Michael A, Rob S, Rajib A, Lindsay B, Saifuddin A, Michelle H. Domestic violence and early childhood mortality in rural India: evidence from prospective data. Inter J of Epidemiology. 2010;39:825-33. https://doi.org/10 1093/ije/dyq066

36. Pool MS, Otupiri E, Owusu-Dabo E, de Jonge A, Agyemang C. Physical violence during pregnancy and pregnancy outcomes in Ghana. BMC Pregnancy Childbirth. 2014;14:71 https://doi.org/10.1186/1471-2393-14-71. PMID: 24528555 [Indexed for MEDLINE].

37. Teji K, Dassie Y, Assefa N, Gobena T. Determinants of Neonatal and Infant Mortality in Kersa Demographic and Health Survey, Eastern Ethiopia: a case control study. Harar: Ethiopia: Haramaya University; 2012. http://www.scribd. com/doc/86593568

38. Gemeda DH. Determinants of neonatal mortality in Gilgel gibe field research center: a matched case control study. Jimma: Ethiopia; 2012 https://www.researchgate.net/profile/Desta_Hiko

39. Mats M. Neonatal mortality: an invisible and marginalized trauma. Department of Women and Children's Health, Uppsala University, Sweden. Glob Health Action. 2011:4:5724. https://doi.org/10.3402/gha.v4i0.5724.

40. William D. Power calculation for matched case control studies. Vanderbilt University School of Medicine, Nashville. 2000;44(4):1157-68. https://www. jstor.org/stable/2531743. 